\title{
O CULTIVO dA LÍNGUA E A TRADUÇÃo NA ALEMANHA NO SÉCULO XVII
}

\section{Stéfano Paschoal*}

\begin{abstract}
RESUMO: Apresentarei neste artigo a tradução de um diálogo sobre estrangeirismos, retirado do segundo volume dos Frauenzimmer Gesprächspiele (1641-1649), de Georg Philipp Harsdörffer (1607-1658). Os estrangeirismos são um dos muitos temas abordados pelos teóricos e intelectuais que discutiam a língua alemã no século XVII. Discutirei a relevância destas observações para a tradução na Alemanha no século XVII.
\end{abstract}

UNITERMOS: estrangeirismos; Alemanha; século XVII; cultivo da língua; tradução.

ABSTRACT: In this paper will be considered the translation of a dialog on foreign words from the second volume of Georg Philipp Harsdörffer's (1607-1658) Frauenzimmer Gesprächspiele (16411649). Foreign words are among the most frequent themes in theoretical discussions about German language in the $17^{\text {th }}$. century. I will discuss the relevance of these considerations for translation in $17^{\text {th }}$. century Germany.

KEYWORDS: foreign words; Germany; $17^{\text {th }}$. century; language policy; translation.

\section{Introdução}

Este artigo compõe-se da discussão sobre o status dos estrangeirismos na língua alemã no século XVII, contido num

\footnotetext{
O autor é doutorando do programa de Pós-Graduação na Faculdade de Filosofia, Letras e Ciências Humanas da Universidade de São Paulo - SP, na área de Língua e Literatura Alemã.
} 
diálogo retirado do segundo volume dos Frauenzimmer Gesprächspiele, de Georg Philipp Harsdörffer (1607-1658), e traduzido por mim. Tomei a liberdade de modernizar a ortografia do texto original de Harsdörffer de forma a evitar problemas de compreensão para o leitor que o queira ler em alemão. As estruturas do texto e mesmo das palavras não mais correntes nos dias de hoje, à exceção de bedüncken, substituída por scheinen, foram mantidas. Não tenho o intuito de, com esta tradução, reconstituir traços estilísticos do texto original, contentando-me com a transmissão de seu conteúdo. São personagens do diálogo: Degenwert von Ruhmeck, um soldado culto; Vespasian von Lustgau, um velho cortesão; Raymund Discretin, um estudante viajado e experiente; Julia von Freudenstein, uma matrona perspicaz; Angelica von Reuschwitz e Cassandra Schönliebin, nobres senhoras.

Os estrangeirismos são um dos diversos temas abordados pelo cultivo da língua na Alemanha no século XVII. Por "cultivo da língua" entendemos o conjunto de discussões de cunho lingüístico na Alemanha no século XVII. O cultivo da língua, em alemão Sprachpflege, era denominado no século XVII Spracharbeit, e gerou a publicação de várias obras que discutiam as formas de escrever o alemão em seu estágio de transição denominado Frühneuhochdeutsch.

As discussões sobre a aceitação ou não de estrangeirismos numa língua não se restringem à Alemanha no século XVII. Ocorreram no movimento cultural que pregava o cultivo da língua em países como Itália e França, num período anterior, conforme comprovam as publicações de De Vulgari Eloquentia (1305), de Dante Alighieri (1265?-1321), e Défense et illustration de la langue française (1549), de Joachim du Bellay (1522-1560). Embora as obras de Dante e de Du Bellay tenham cooperado para a sistematização de regras da língua italiana e da língua francesa, respectivamente, dando a elas autonomia e desvinculando-as do estilo latinizante, a primeira (de Dante) foi escrita em latim.

A aceitação de estrangeirismos numa determinada língua é, até os dias de hoje, um assunto polêmico. Para exemplificar, podemos mencionar a resistência de alguns países quanto à 
aceitação do grande número de anglicismos em seu léxico. Devese ressaltar que a ocorrência de anglicismos em línguas ocidentais é uma conseqüência do advento tecnológico, político, industrial e econômico dos Estados Unidos da América, após a Segunda Guerra Mundial.

A França, onde recentemente houve um movimento cultural que pregava a "proibição" de vocábulos ingleses na língua escrita, é o exemplo que ilustra mais adequadamente a resistência ao uso de estrangeirismos nos dias de hoje. No Brasil, os estrangeirismos (anglicismos) não são tão fortemente combatidos e, na Alemanha, há apenas uma preocupação em relação ao tema, geralmente veiculada por revistas e jornais de alcance popular.

Considerando que até mesmo para a língua latina, já há muito não falada, existe uma comissão responsável pela criação de termos como apparatus frigorificus e capsula sulfuraria, perguntamo-nos se os responsáveis pelo vernáculo deveriam ou não admitir a "invasão" de palavras estrangeiras.

Apesar da atualidade do tema, o nosso foco recai sobre a discussão apresentada por Georg Philipp Harsdörffer (16071658), num contexto diverso do atual: a Alemanha no século XVII, onde, por conseqüência da Guerra dos Trinta Anos (16181648) e de um currículo que privilegiava o latim, a língua alemã, num de seus estágios de transição, não encontrava espaço para seu desenvolvimento.

A Guerra dos Trinta Anos (1618-1648), que atingiu toda a Europa e mais fortemente o território alemão, provocou um grande deslocamento de tropas e de fugitivos civis de vários países, cooperando assim para um caos lingüístico, ocorrido na língua alemã principalmente através da mistura de vocábulos estrangeiros.

Num país em que a união nacional ocorreria apenas em 1871 - objetivo quase utópico no século XVII - restava à língua e às manifestações culturais e literárias o papel de elemento identificador das populações lá residentes. Além disso, não havia na Alemanha uma produção destinada a sistematizar o vernáculo que colaborasse para sua constituição literária, conforme já havia ocorrido em países vizinhos. Uma língua que servisse 
às manifestações culturais de um povo como símbolo de identificação deveria passar por um processo de "purificação" (Sprachreinigung).

No que se refere ao currículo escolar na Alemanha no século XVII, devemos elucidar que sua base era o estudo da Retórica, em latim, já que esta era a língua de prestígio dos intelectuais e das ciências. Nas aulas, eram privilegiados os exercícios de imitação, em que não apenas conteúdos, mas também estilos de grandes autores da Antigüidade, deveriam ser imitados. O modelo principal para as imitações eram textos de Cícero (10643 a.C.).

Não obstante os esforços de Wolfgang Ratke (1571-1635) para a inclusão do alemão no currículo escolar e a conseqüente supressão do latim, é apenas através de Christian Weise (16421708) que o alemão deixa de ser uma língua auxiliar, utilizada em exercícios de tradução, e passa a ser a língua principal do currículo. Para ilustrar a situação da sobreposição do latim ao alemão, mencionamos aqui que o número de publicações em alemão na Alemanha somente em 1683 superou o de publicações em latim.

O conteúdo expresso no diálogo apresentado e traduzido a seguir não representa apenas um texto isolado de um Gesprächspiel, ${ }^{1}$ mas revela ecos de uma tendência das academias ${ }^{2}$ (Sprachgesellschaften) surgidas na Alemanha no século XVII, de que Georg Philipp Harsdörffer fazia parte. Dentre outras obras desta mesma época, em que podem ser encontradas discussões sobre estrangeirismos, podemos mencionar: Aristarch (1617) e Buch von der Deutschen Poeterey (1624), de Martin Opitz (15971639), Lobrede der Deutschen Poeterey (1645), de Johann Klaj (1616-1656), Poetischer Trichter (1653), de Georg Philipp Harsdörffer (1607-1658), Ausführliche Arbeit der Teutschen Haubtsprache (1663), de Georg Justus Schottelius (1612-1676), e An-

\footnotetext{
1 Os Frauenzimmer Gesprächspiele eram revistas de distração para público feminino.

2 A tradução literal de Sprachgesellschaften seria "sociedades lingüísticas". Optamos aqui por "Academia", já que em português este é o termo mais apropriado para designar as instituições que cultivavam a lingua.
} 
leitung zur deutschen Poeterey (1665), de August Buchner (15911661).

\section{Tradução}

1. (Degenwert) Das SCH kommt Fremde / so unsere Sprache lernen wollen / sehr schwer an auszusprechen / weil nämlich solche Wörter von dem Hebräischen oder Altdeutschen / keines aber meines Wissens von dem Lateinischen herkommt / welches heutzutage in der Französischen / Welschen / oder auch kaum bei der Spanischen (als der Lateinischen Sprache wohl erzogenen Töchtern) gebräuchlich wäre. Nun wollte ich wohl auch andere Buchstaben bedingen / wann ich der Gesellschaft mit Wiederholung einerlei Sache nicht verdrießlich zu sein befürchtete. Will deswegen von den Buchstaben zu den Worten schreiten / und vom deutschen Bürgerrecht fremder Wörter mich Berichts erholen.

1. (Degenwert) O som SCH é dificil de pronunciar para estrangeiros que querem aprender a nossa língua, pois as palavras que o contêm originam-se do hebraico ou do antigo-alemão; nenhuma, no entanto, segundo meus conhecimentos, do latim, e pouco se usa este som na lingua francesa, na italiana ${ }^{3} \mathrm{e}$ na espanhola (que podem ser consideradas as filhas legitimas do latim). Se não me importasse que os leitores se irritassem com a repetição de tais coisas, incluiria outros sons. Passarei, por isso, das letras às palavras, e tratarei da cidadania alemã de palavras estrangeiras.

2. (Vespasian) Es ist ein feiner Vortrag / der nicht ein Gesprächspiel / sondern zu Richtigkeit und rühmlichen Aufnahme unserer Sprache / ein ganzes Buch erforderte. Der Herr vermelde / wie das Spiel anzuordnen vermeint.

2. (Vespasian) Este é um relato sutil que exigiria para a correção e recepção prestigiosa de nossa língua não um diálo-

\footnotetext{
3 O vocábulo utilizado no original, Welsch, é nos dias de hoje mais usado para referir-se ao francês.
} 
go, ${ }^{4}$ mas sim um livro todo. Peço ao Senhor que indique as regras.

3. (Degenwert) Es soll dieses Orts nicht von denen Wörtern die Frage sein / welche von Ankunft Deutsch / oder von dem Hebräischen herstammen / von denen bereit Meldung beschehen: sondern ich bitte / dass jedes drei Wörter vorschlagen wolle / welche nicht vom Hebräischen, sondern vom Lateinischen / oder dem Latein verwandten Sprachen / Welschen / Französischen oder Spanischen herkommen / und zu dem deutschen Stadtrecht zuzulassen sein möchten. $Z u$ solchem Spiel bin ich veranlasst worden / durch die mir angedrohte Strafe / des Wassertrinkens / wann ich / wie sonsten gebräuchlich undeutsche Wörtlein einwerfe / deren ich mich nicht ohne Mühe enthalte. Gewiss ist / dass der Gebrauch vielmals verständige Ursachen zu Boden druckt: oder deutlicher zu sagen / dass der Missbrauch durch Verlauf der Zeit sich allen guten Gewohnheiten einflicht und selbe unterbricht. Nun haben zwar die alten Deutschen / eine Sprache / ihrem rauhen Land und verwildten Gewohnheiten ähnlich geführt. Jedoch schreibt man / dass die Völker über den Rhein zu der römischen Kaiser Zeiten / und auch lang bevor / der Ihrigen Heroischen Taten bei ihren Gräbern zu singen und zu rühmen gewohnt / von welchen die noch heutzutage in etlichen Reichstädten befindliche Meistersinger herkommen sollen. Nachmals aber / als die Römer teils durch die Waffen / teils durch Kaufmannschaft sich mit den Deutschen bekannt zu machen / und sich unter sie zu vermischen angefangen / haben zugleich die Sprachen miteinander vermengt werden müssen: sonderlich aber in solchen Sachen/ welche den Deutschen bevor ganz unbekannt und notwendig mit fremden Worten auszureden gewesen. Bis endlich Carolus genannt der Grosse / mit dem Reich auch die Sprache zu erheben angefangen. Jedoch hat man dazumal noch nicht Deutsch schreiben können / sondern in Befehlen / Befreiungsbriefen und öffentlichen Schriften hat man sich des Lateins bedient / bis auf das Jahr 1243 und hernach erst das Deutsche mit lateinischen Buchstaben zu schreiben 4 Gesprächspiel é um diálogo com fins de distração. Trata-se aqui de uma
brincadeira. 
begann / daher ich dann in den unvergreiflichen Wahn stehe / man solle die Bastardwörter / welche durch beider Sprachen Verehelichung und Vermischung von unerdenklichen Zeiten legitimiert worden / nicht mit Schand und Schmach auszurotten und auszumustern begehren / sondern selbe als Einkömmling erdulden. In sonderlichem Bedenken / dass man vielmals die vermeinten deutschen Wörter weniger / als das lang gewohnte halb Lateinische verstehen kann / und die allzu lang eingewurzelte Art zu reden / nicht wohl auszureuten tunlich sein wird. Will man aber das Lateinische beisetzen / so ist es nicht anders / als wie die Ägypter ihren ungeschickten Gemälden beizuschreiben gewohnt: das soll ein Ochs / das soll ein Löwu. sein / und scheint / es sei solche Art / wider deutscher Schriften vermeinten Wohlstand.

3. (Degenwert) Não se deve tratar aqui daquelas palavras que sejam de origem alemã ou daquelas advindas do hebraico, ${ }^{5}$ das quais já se tem notícia, mas sim, peço que cada um sugira três palavras não-oriundas do hebraico, e sim do latim, ou de línguas neolatinas, como o italiano, o francês ou o espanhol, às quais se poderia dar a cidadania alemã. Fui levado a entrar nessa brincadeira com a advertência de ser submetido à punição de tomar água, caso, como é de costume geral, misturasse em minha fala palavras alheias, das quais não me abstenho sem esforço. É certo que, freqüentemente, o uso se sobrepõe a causas compreensiveis: ou, mais claramente dizendo, com o passar do tempo, o mau uso mistura-se a todos os bons hábitos, exterminando-os. É verdade que os antigos alemães criaram uma língua semelhante à sua terra rude e a seus hábitos bárbaros. Escreve-se, contudo, que os povos do outro lado do Reno, ${ }^{6}$ nos tempos dos imperadores romanos, e já bem antes, costumavam cantar e louvar os atos heróicos de seus parentes em frente aos seus túmulos, costume do qual devem ter se originado os mes-

5 Vale lembrar aqui que, assim como Harsdörffer, também outros teóricos desta época defendiam que o alemão se originava do hebraico - um recurso para colocar a lingua alemã no mesmo nivel das linguas sagradas (hebraico, grego e latim).

6 Optei pela tradução "do outro lado do Reno", já que se remete no diálogo à perspectiva romana, de Tácito. 
tres-cantores em várias cidades-livres, existentes até os dias de hoje. Depois, todavia, quando os romanos, ora através das armas, ora do comércio, travaram conhecimento com os alemães, e começaram a se misturar com eles, as línguas também tiveram de se misturar, principalmente tratando-se de coisas anteriormente desconhecidas pelos alemães, para cuja expressão foi necessário o uso de palavras estrangeiras, até que, finalmente, Carolus, denominado Magnus, começou a erguer, junto com o Império, a língua. Nesta época, porém, não se escrevia em alemão. Ao contrário disto, até o ano de 1243 usava-se o latim nos decretos, indultos e escrita pública, e só a partir daí começou-se a escrever em alemão com letras latinas, motivo pelo qual estou irracionalmente convencido de que não se deve desejar extinguir e exterminar com vergonha e desonra as palavras bastardas, legitimadas há tempos impensáveis pelo matrimônio e pela mistura das duas linguas; mas sim tolerar essas palavras como hóspedes. O que foi dito se mostra verdadeiro, considerando-se em particular que muitas vezes se podem entender as supostas palavras alemãs apenas com mais dificuldade do que o latim misturado com que se está acostumado e que não faria sentido exterminar a maneira de falar enraizada já há muito tempo. No entanto, quem quiser colocar explicações em latim ao lado do texto em alemão não agirá de maneira diferente dos egípcios, que costumavam acrescentar aos seus desenhos desajeitados explicações por escrito: esse desenho representa um boi e aquele, um leão etc., e parece que a estratégia de explicar o sentido do texto alemão mediante comentários intercalados em latim é contra o suposto bem-estar dos escritos em alemão.

4. (Raymund) Unter den alten Deutschen / und den Neuen / (ich will sagen den unsrigen Zeiten) / ist ein merklicher Unterschied. Damals sind sie in Unwissenheit aller Künste / ja auch des christlichen Glaubens gesteckt / nachmals ist die Kunst in den Klöstern und Klausen versteckt / und dem gemeinen Mann verborgen gewesen. Wie dann die Reden- und Schreibensart von zweihundert Jahren her ganz geändert worden? Heutzutage / haben wir die hohen Wohltaten der Druckerei / dass dem gemeinen Mann Tür und Tor / alles und jedes / zu lernen und zu erkündigen offen steht. So ist es auch mit der Maler groben Pinsel 
bewandert gewesen; jetzt aber kommt die Kunst der Natur so ähnlich nach / dass man fast dazu schreiben muss / es sei nur gemalt. Wann nun unsere Sprache so vollkommen / und wie erweislich / noch Deutsch in Deutschland ist, warum wollen wir unsere Zunge mit anderen Wörtern beflecken / die Kinder verächtlich hinausstoßen / und die Bastardwörter an- und aufnehmen?

4. (Raymund) Há uma diferença substancial entre os antigos alemães e os novos ${ }^{7}$ (quero dizer, os de nosso tempo). Antes se encontravam na ignorância de todas as artes e também da fé cristã. Depois disto, a arte manteve-se secreta nas celas e mosteiros, escondida do homem comum. Como, então, a forma de falar e de escrever se modificou totalmente de duzentos anos para cá? Hoje em dia temos as benfeitorias da Imprensa, que abre ao homem comum todas as portas, permitindo a todos que aprendam e se informem sobre toda e qualquer coisa. Assim também ocorreu com o pincel rude do pintor: agora, no entanto, a arte se assemelha tanto à natureza, que é necessário advertir que se trata apenas de uma obra de arte. Se a nossa língua neste momento está tão completa e, como dito, é língua alemã na Alemanha, por que devemos manchá-la com outras palavras e desdenhosamente impô-la aos mais jovens, aceitando e incorporando estas palavras bastardas?

5. (Degenwert) Der Herr gebraucht sich selbst des Worts Bastard / welches von dem Französischen Bastard, oder Italienischen und Spanischen Bastardo entsprungen.

5. (Degenwert) O Senhor mesmo utiliza a palavra bastar$d a$, originada do francês bastard, ou do italiano e espanhol bastardo.

6. (Raymund) Der Herr vergebe mir / wann ich nicht seiner Meinung bin / dann Bastard ein altdeutsches Wort ist / und vielmehr solches Fremde von uns / als wir von ihnen geborget haben möge: Dann es kommt her von dem Bast / mit welchem man die Pfropfreiser der inwendigen safftigen Rinden einverleibt / bekleibt und anwachsen macht / und dem Wörtlein Art / das ist eine Art / welche mit andern durch das Bast verbunden und gleichsam geimpft wird.

7 Opto pela tradução "alemães" em vez de "germânicos". 
6. (Raymund) Queira perdoar-me o Senhor, que eu não tenha a mesma opinião, mas bastard é uma palavra do antigo-alemão ${ }^{8}$ e, antes, creio mais que os estrangeiros a emprestaram de nós, do que nós a emprestamos deles. Deriva-se de "bast"("ráfia"), com a qual se enxerta, aglutina e deixa crescer o novo ramo da cortiça suculenta da outra árvore, e a palavra "Art", que é a espécie que se amarra à ráfia e que é da mesma forma enxertada. ${ }^{10}$

7. (Degenwert) Herr Vespasian soll unser Richter sein.

7. (Degenwert) O Senhor Vespasian deve ser o nosso juiz.

8. (Vespasian) $\mathrm{Ob}$ ich zwar mich lieber von andern richten lasse / als dergleichen sorgsamen Amts unterfange; So will ich doch nach meinem wenigen Verstand unmaßgeblich entdecken/ was mir von der Herren Streit scheint. Die fremden Wörter / welchen das deutsche Bürgerrecht erteilt werden soll / müssen dreierlei folgende Eigenschaften haben:

I. Dass selbe in unserer Sprach ermangeln / oder ohne Umschreibung nicht füglich auszureden sein.

II. Dass solches Wort bereit bei jedermann bekannt / und auch von denen / welche anderer Sprachen nicht kundig / verstanden werden.

III. Dass selbe sich bürgerlich halten / ich will sagen / deutsch geschrieben / und deutsch geendet werden.

Jedoch will ich / wie gedacht / diese Meinung / mehr verständigen hilfsreichen Erachten willig unterwerfen / und nach Bericht jederzeit zu ändern erbietig verbleiben / erinnere mich hierbei / dass jener sagt / es scheint ihm / wann er höre fremde und deutsche Wörter untereinander vermengen/ und gleichsam verunehlichen / es küssle ihm ein Floh im Ohr.

\footnotetext{
8 A palavra bastard origina-se do francês. A informação de cunho etimológico fornecida aqui não procede, todavia revela a tendência de atribuir ao alemão a origem de todas as coisas.

9 "Bast" é uma fibra vegetal que se encontra por baixo do córtice de árvores ou em plantas como o cânhamo, o sisal e o linho (no Brasil, utilizam-se mais freqüentemente as folhas das palmeiras), para fins artesanais. O uso citado aí refere-se à técnica de enxerto (colocar o ramo de uma árvore cultivada numa árvore selvagem), processo muito antigo e usado na Europa para cultivar frutas como maçã, pêra, pêssego, cereja. Para que o novo ramo floresça no tronco da árvore, fixa-se-lhe com um fio de Bast (liber, ráfia) dentro da cortiça (Rinde) da árvore selvagem.

10 "Enxerto", aí, remete-nos à mistura de línguas.
} 
8. (Vespasian) Embora eu prefira deixar-me ser conduzido do que julgar o trabalho cuidadoso dos outros, quero esclarecer, despretensiosamente, segundo meus poucos conhecimentos, o que penso da briga dos senhores. As palavras estrangeiras às quais deve ser dada cidadania alemã devem possuir as três características seguintes:

I. Que as mesmas não existam em nossa língua ou que não possam ser pronunciadas sem serem parafraseadas;

II. Que uma tal palavra seja prontamente entendida por qualquer pessoa, inclusive por aqueles que não têm habilidades em outras linguas;

III. Que as mesmas mantenham a cidadania, quero dizer, que sejam escritas em alemão e que recebam terminação alemã.

No entanto, quero, como pensado, subjugar esta opinião a um parecer mais compreensivel e de mais ajuda e, conforme relatado, ficar espontaneamente sujeito a mudanças a qualquer tempo. Lembro-me aqui daquele que diz que parece ter uma pulga fazendo-lhe coçar o ouvido quando ouve palavras alemãs e estrangeiras misturadas e de forma bagunçada.

9. (Degenwert) Nun wollen wir unter diesen Regeln die Exempel / oder nach des Herrn Weise zu reden / unter diesen Lehrsatz die Beispiel setzen: campieren / canonieren / marchieren $u$. sind so gebräuchliche und jedermann verständige Wörter / dass ob sie wohl aus fremden Ländern zu uns gelangen / sie doch wo nicht für Bürger / jedoch für Angesessene und Stadtsgenossen / nicht mehr werden auszuschaffen sein.

9. (Degenwert) Queremos, então, dar os exemplos referentes a estas regras ou, segundo a forma de dizer do Senhor, ${ }^{11}$ introduzir os exemplos de acordo com esta teoria: campieren, canonieren, marchieren ${ }^{12}$ etc. são palavras entendidas por todos e tão comuns que, embora tenham chegado de terras estranhas

11 Conforme se pode ver no original, a personagem do diálogo repete a mesma informação, porém de formas diferentes. Na primeira vez, utiliza palavras advindas do latim e, na segunda, palavras "originalmente" alemãs.

12 "Acampar", "atirar com canhões", "marchar". 
até nós, se não julgadas cidadãs, devem ao menos ser consideradas domiciliadas ou concidadãs.

10. (Vespasian) Eine böse Gewohnheit / kann kein gutes Gesetz heißen. Ich bekenne zwar gern / dass wann ich bei Soldaten mich befinde / dass ich dergleichen Wort zu gebrauchen nicht Bedenken tragen wollte: unter Frauenzimmern aber / oder Liebhabern der reinen deutschen Sprache wollte ich sagen: zu Feld liegen (campieren) / mit Stücken beschießen (canonieren), ziehen oder reisen (marchieren u.) daher die Alten den Heerzug / den Marsch genannt.

10. (Vespasian) Um mau costume não pode ser considerado uma boa lei. Reconheço, é verdade, que, entre soldados, não sentiria desconforto em usar estas ou aquelas palavras, porém entre senhoras ou entre amantes da língua alemã eu preferiria dizer zu Feld liegen (campieren); mit Stücken beschießen (canonieren) e ziehen ou reisen (marchieren), ${ }^{13}$ pois os antigos chamavam o Heerzug (expedição militar) de Marsch.

11. (Julia) Es ist gewisslich lächerlich / wann die aus Frankreich wiederkommenden jungen Gesellen / unter dem Deutschreden nur etliche Französische Wörter mit einquatschen / und nicht eine Sprache ohne die andere reden wollen / noch aus Gewohnheit reden können. Jedoch frage ich / (dem Spiel ein Genügen zu tun) / ob nicht diese fast von allen und jeden angenommenen Wörter: die Dame / der Cavalier / die Compagnie u. zuzulassen?

11. (Julia) É certamente risivel quando os jovens oficiais, recém-chegados da França, ao conversarem em alemão, incluem palavras francesas e não querem ou, ainda, não conseguem, por força do hábito, falar uma língua sem intervenção da outra. Eu, contudo, me pergunto (para cumprir as regras da brincadeira) ${ }^{14}$ se palavras incorporadas por quase todas as pessoas, como die Dame, der Cavalier, die Compagnie, não devem ser permitidas.

\footnotetext{
13 Os termos que precedem as palavras campieren, canonieren e marchieren, entre parênteses no parágrafo onde está a indicação desta nota, cujo significado foi elucidado na nota anterior, são opções de como as expressar em alemão "puro".

14 Lembremo-nos de que este diálogo, na verdade, é uma brincadeira entre amigos.
} 
12. (Vespasian) Es kann niemand hierin Ziel und Maß (wie unterschiedlich erwähnt) vorgeschrieben werden. Ich stehe in den unvergreiflichen Gedanken / es laute besser / die Jungfrau oder Frau / als die Dame; der Rittersmann / als Cavalier / die Gesellschaft oder Genossenschaft / als Compagnie / oder in anderem Verstand ein Fahnen oder Fähnlein Soldaten. Dann die Wörter sind gleich den Rechnenpfennigen / wie man sie legt / so gelten sie / wie man sie gebraucht / so müssen sie verstanden werden.

12. (Vespasian) Não se pode aqui prescrever pesos e medidas a ninguém (conforme mencionado em várias oportunidades). Mantenho a opinião de que soa melhor dizer die Jungfrau ou Frau $^{15}$ do que die Dame; der Rittersmann ${ }^{16}$ do que der Cavalier; die Gesellschaft ou Genossenschaft ${ }^{17}$ do que Compagnie, ou, em outra acepção, ein Fahnen ou Fähnlein Soldaten (uma companhia de soldados), ${ }^{18}$ pois as palavras assemelham-se ao centavo utilizado nas aulas de aritmética, ${ }^{19}$ que valem da forma como são colocados, mas que devem ser entendidos da forma como são usados.

13. (Angelica) Man sagt im Sprichwort / wann man unter den Wölfen ist / so muss man mit heulen. Sonderlich / weil sehr verhasst / und bisweilen gefährlich / etwas besonders einführen / und Handhaben wollen. Dann wer will den jungen Leuten das meritieren / servieren / obligieren u. aus dem Mund nehmen / und sie zugleich nicht fast verstummen machen?

13. (Angelica) Diz o provérbio, que, estando entre os romanos, deve-se comportar como eles, ${ }^{20}$ principalmente porque é pouco aceitável incluir um conceito novo e querer usá-lo de imediato. Quem desejaria privar os jovens das palavras meritieren,

\footnotetext{
15 "Senhorita", "senhora".

16 "Cavaleiro".

17 "Companhia".

18 Fahnen ou Fähnlein significa, na terminologia militar da época, "companhia de soldados", também chamada de "bandeira" (Fahne) na legislação militar portuguesa do século XVI.

19 O Rechnenpfennig - centavo para fazer contas - era utilizado nas aulas de aritmética para que se praticassem as operações de soma e subtração. Apresentava apenas valor simbólico.

20 Houve adaptação na tradução deste provérbio.
} 
servieren, obligieren ${ }^{21}$ etc. sem ao mesmo tempo praticamente emudecê-los?

14. (Vespasian) Diese sind uns ganz unnötige Wörter / und scheint mir / es klinge besser / so ich sage: Ich achte mich dieser Gunst unwürdig / und verbunden selbe auf alle Begebenheit / äußersten Vermögens zu bedienen $u$. Als: Ich meritiere die gratiam nicht / und bin obligieret, dem Monsieur wiederum omnibus viribus zu serviren. Dame und Cavalier sollten noch ehe erduldet werden können / als erstbesagte Arten zu reden.

14. (Vespasian) Estas são palavras totalmente desnecessárias para nós, e parece-me que soa melhor dizer "Ich achte mich dieser Gunst unwürdig und verbunden selbe auf alle Begebenheit / äußersten Vermögens zu bedienen" do que "Ich meritiere die gratiam nicht/ und bin obligieret/ dem Monsieur wiederum omnibus viribus zu servieren". ${ }^{22}$ Dame e Cavalier podem, no entanto, ser mais toleradas do que esta forma de falar.

15. (Raymund) Diese Wörter firmament, discretion, fundament \&c. können so wohl wegen ihrer Endungen / als Erkenntnis deutsch geschrieben / und nicht mehr für fremde gehalten werden.

15. (Raymund) Palavras tais como firmament, discretion, fundament ${ }^{23}$ etc. podem, tanto por causa de seu conteúdo quanto de suas terminações, ser escritas em alemão, e não podem ser consideradas estrangeiras.

16. (Vespasian) Es wird niemand in Abrede sein / dass die von anderen Ländern zu uns gebrachte Gewächs / Früchten / Blumen / Gewürz und Kleidungsarten / mit fremden Namen zu nennen / weil selbe durch den Gebrauch gleichsam gedeutscht werden / als Zitronen / Tulipanen / Indigo / Muscat u. firmament aber kann heißen die Feste des Himmels / discretion Bescheidenheit / fundament ein Grund / u. Gewisslich es ist uns Deutschen viel rühmlicher / unsere Sprache auszuüben / als selbe

\footnotetext{
21 "Prestar méritos ou favores", "servir", "estar obrigado a".

22 As duas sentenças aí apresentadas têm o mesmo significado: "Creio ser este favor indigno de mim e sou obrigado a servir ao Senhor com todo esforço e em qualquer condição"; a primeira, em alemão livre de estrangeirismos, e a segunda, carregada deles.

23 "Firmamento", "discreção" e "fundamento".
} 
mit anderen Worten beschämen / ausflicken / durch fremde Wörter verdunkeln und nach und nach ganz verderben und vernichten. Da wir vielmehr bemüht sein sollten / auch die Kunstwort (terminos artis) so viel tunlich / auszureden / und verständlich mit nachdrücklichen Bedeutungen zu deutschen / wie Stevin in Niederland getan / und es dahin gebracht / dass man des Lateins so wohl / als der Granatäpfel entraten kann.

16. (Vespasian) Ninguém negará o fato de que plantas, frutas, flores, temperos e vestidos, que nos são trazidos de outras terras, recebam nomes estrangeiros, porque os mesmos, mediante o uso, são germanizados, como Zitronen, Tulipanen, Indigo, Muscat ${ }^{24}$ etc. Firmament, no entanto, pode se chamar Feste des Himmels, ${ }^{25}$ discretion, Bescheidenheit, ${ }^{26}$ fundament, ein Grund ${ }^{27}$ etc. Certamente é mais louvável para nós, alemães, exercer nossa lingua, do que a envergonhar e sujar e, mediante o uso de palavras estrangeiras, obscurecê-la, arruinando-a e exterminando-a pouco a pouco. Devemos, sim, nos encorajar mais ainda e pronunciar e germanizar de forma compreensivel e com significado exato os termos técnicos (terminos artis), ${ }^{28}$ assim como Stevin, ${ }^{29}$ na Holanda, fez com que se pudesse prescindir do latim tanto quanto das romãs. ${ }^{30}$

17. (Cassandra) Wollte der Herr nicht passieren lassen / wann ich sage / der Autor / das Proviant / der Potentat.

17. (Cassandra) O Senhor não deixaria passar, se eu dissesse der Autor, das Proviant, der Potentat? ${ }^{31}$

\footnotetext{
24 "Limão", "tulipas", “anileiro" e "noz-moscada".

25 "Firmamento".

26 "Modéstia".

27 "Fundamento".

28 Atentemos nesta parte do diálogo para a necessidade de se "germanizarem" também os termos técnicos - uma tarefa da Terminologia no século XVII, dada a intelectuais responsáveis pelo cultivo da língua.

29 Simon Stevin (1548-1620), cientista e matemático flamengo, que escreveu todas as suas obras em holandês.

30 Esta comparação pode ser interpretada de duas formas. A primeira refere-se ao grau de facilidade de prescindir de uma língua; isto é tão fácil quanto prescindir de um fruto que não é natural de seu país. A segunda interpretação nos leva ao entendimento de romã como representação do estrangeiro.

31 "Autor", "mantimentos" e "potentado".
} 
18. (Vespasian) Nicht passieren / sondern gelten ${ }^{32}$ können solche Wörter / weil sie deutsch geendet / von jedermann verstanden / und deutsch geschrieben werden. Im Fall aber ich sollte deutschen Chapperon garçettes, galouches \&c. müsste ich entweder diese Wörter noch zur Zeit behalten oder so beschreiben und umschreiben / dass mich die / mit welchen ich davon rede / verstehen.

18. (Vespasian) Não é o caso de deixar passar, mas tais palavras são válidas porque apresentam terminação alemã, são entendidas por todos e são escritas em alemão. Porém, se eu tivesse que germanizar Chapperon garçettes, galouches ${ }^{33}$ etc., teria que ou por ora mantê-las ou parafraseá-las, de forma que aqueles, com quem eu conversasse a este respeito, pudessem entender-me.

\section{Comentários do diálogo traduzido}

No início do diálogo, Degenwert aponta o som produzido pelas letras "sch" como ocorrente em palavras derivadas do antigo-alemão e do hebraico. Uma das tendências do cultivo da língua na Alemanha no século XVII era atribuir à língua alemã parentesco com o hebraico, o que conseqüentemente alterava o status da língua, que estaria assim relacionada à língua original da Escritura Sagrada. Outras formas de alteração do status da língua alemã são encontradas nos elogios, presentes em obras como Aristarch (1617), de Martin Opitz (1597-1639), e Lobrede der Teutschen Poeterey (1645), de Johann Klaj (1616-1656).

O tema do diálogo aqui apresentado e traduzido - os estrangeirismos e a discussão sobre sua incorporação à língua alemã - é pertinente ao cultivo da língua realizado nessa época e relaciona-se ao movimento de purificação da língua (Sprachreinigung).

Em (3), Degenwert explica as regras da brincadeira proposta no diálogo: devem-se citar três tipos de estrangeirismos

\footnotetext{
32 Não foi possível aqui recuperar o jogo de palavras no original, a saber "passieren" e "gelten", em que há a substituição do estrangeirismo "passieren" por "gelten".

33 "Capuz", "cabelo trançado", "galocha".
} 
que possam, em seu "estado natural", ser incorporados à língua. Estes estrangeirismos devem ser provenientes do latim, do francês, do espanhol ou do italiano.

No diálogo, são apresentadas duas concepções quanto ao uso de estrangeirismos: a de que devem ser eliminados da língua alemã e a de que devem ser incorporados - a primeira defendida por Raymund e Vespasian e; a segunda, por Degenwert.

A visão de Degenwert é ilustrada pelo discurso que aborda o contato entre alemães e romanos e, desde essa época, a mistura do latim ao idioma alemão. Uma vez que Degenwert considera a incorporação de latinismos ao idioma alemão algo natural, ocorrido através do processo histórico, julga absurda a idéia de que sejam eliminados. Reforça ainda que os vocábulos latinos germanizados eram mais compreendidos do que os alemães "legítimos".

Em (4), Raymund evoca o panorama histórico do século XVII, em que aponta a diferença entre o homem alemão da era de Carlos Magno e aquele da era pós-imprensa. No final desse parágrafo, encontram-se características de cunho nacionalista, quando o personagem questiona o desmerecimento com a língua através da inclusão de estrangeirismos e de sua perpetuação, bem como na discussão posterior, a respeito da origem da palavra bastard, de origem francesa, à qual atribuiu origem alemã.

A sistematização dos requisitos necessários para que um vocábulo seja incorporado à língua alemã ocorre em (8). Resumidamente, estes vocábulos devem pertencer às categorias seguintes:

a) palavras inexistentes em língua alemã;

b) palavras que sejam entendidas por todos;

c) palavras que sejam adaptáveis à ortografia e à gramática alemãs.

Desse ponto até o final do diálogo, sugere-se a incorporação à língua alemã das seguintes palavras: campieren, canonieren, marchieren, Dame, Cavalier, Compagnie, Soldaten, meritieren, servieren, obligieren, firmament, discretion, fundament, Autor, 
Proviant, Potentat, das quais, segundo a visão apresentada, apenas as três últimas podem ser incorporadas. Nomes de frutas e plantas são mantidos, como Zitronen, Tulipanen, Indigo, Muscat, já que passam por um processo natural de incorporação à língua (germanização).

\section{Cultivo da língua e tradução}

Nesse ponto, será abordado como as discussões sobre estrangeirismos influem na forma de traduzir na Alemanha no século XVII. Podemos definir tradução, grosso modo, como a transmissão de sentidos de um código para outro, levando-se em conta aspectos culturais, espaciais e temporais.

A tradução na Alemanha no século XVII recebia influências da escolarização aí vigente, em que um dos exercícios retóricos mais freqüentes era a tradução de textos antigos, buscando a emulação do original. Com o intuito de superar o original, não apenas conteúdo, mas também estilo era modificado.

Os itens abordados pelo cultivo da língua - cujo exemplo neste artigo compõe-se de discussões sobre a aceitação de estrangeirismos na língua alemã - influíram na tradução na Alemanha no século XVII, embora tratassem mais diretamente de aspectos lingüísticos aplicáveis à escritura de textos originais. $\mathrm{O}$ estilo das traduções, no entanto, é o mesmo dos originais, já que, neste século, a tradução era tarefa destinada a intelectuais envolvidos no processo de cultivo da língua.

No tocante à relação entre estrangeirismos e tradução, consideremos que, para designar tradução, na Alemanha do século XVII, os termos Verdeutschung, Teutschung ou Eindeutschung (o primeiro mais freqüente), que implicam a germanização de estrangeirismos, eram preferíveis a Dolmetschung, Übersetzung, Übertragung. Embora os termos Verdeutschung, Teutschung e Eindeutschung sejam compreendidos nos dias de hoje para veicular a idéia da "germanização" de uma palavra apenas, como, por exemplo, a substituição de Fenster por Tagesleuchter, e não de um texto, eles eram utilizados no século XVII em títulos de traduções, como é o caso da tradução de Los siete libros de la Diana (1559), de Jorge de Montemayor (1520-1562), sob o título 
Die sieben Bücher der schönen Diana (1619), por Hans Ludwig von Kuefstein (1582-1656), que o editor Michael Endter, em 1646, denomina Teutschung.

A idéia de germanização no século XVII não se restringia a encontrar um correspondente em língua alemã para os estrangeirismos, mas estendia-se também a procedimentos de tradução. Se um trecho de uma tradução caísse na obscuridade devido ao excesso de "fidelidade" do tradutor ao original, este era aconselhado ao abandono momentâneo do original e à busca de uma forma "natural" de expressar os conteúdos do original em língua alemã, como vemos abaixo, no trecho que compõe o prefácio da tradução da obra La Diana Enamorada (1564), de Gaspar Gil Polo (1530-1591), para o alemão, realizada por Georg Philipp Harsdörffer (1607-1658):

(...) se eu prefiro manter-me preso às palavras ou me afastar delas com liberdade? Se for ocorrer um erro, então é de mais responsabilidade que se mantenha o pensamento na lingua de chegada, coloque-se o original de lado e deixe-se conduzir pela forma tipica (natural) de falar o alemão. (...) ${ }^{34}$

(...) ob ich lieber mit Zwang bei den Worten bleiben / oder von derselben mit Freiheit abschreiten soll? Wann ja ein Fehler hierin vorgehen muss / so ist verantwortlicher man behalte die Meinung in der Grundsprache / lege das Buch beiseite / und richte es nach der Teutschen Mundart. (...)

Assim, o conceito de traduzir é o de trazer para a língua alemã conteúdos presentes em outras culturas, porém de forma que sejam entendidos pelos leitores alemães e que obedeçam ao funcionamento dessa língua. Com isto, podemos perceber que a discussão sobre a eliminação de estrangeirismos com vistas à produção de um texto com palavras "originalmente" alemãs tem um alcance maior do que se imagina, pois influi também na forma de transmissão de idéias de uma cultura para outra, ou seja, na tradução. As idéias contidas nos originais não deveriam

34 “(...) ob ich lieber mit Zwang bei den Worten bleiben / oder von derselben mit Freiheit abschreiten soll? Wann ja ein Fehler hierin vorgehen muss / so ist verantwortlicher man behalte die Meinung in der Grundsprache / lege das Buch beiseite / und richte es nach der Teutschen Mundart. (...)" 
ser "purificadas", mas sua forma de apresentação deveria se desvincular do estilo proveniente do latim e buscar um estilo autêntico, que pudesse servir como veiculador das manifestações culturais e literárias numa época de caos.

A existência do cultivo da língua na Alemanha no século XVII não podia garantir que nas obras traduzidas nesse período predominasse o uso de vocábulos "originalmente" alemães, pois, mesmo que esse cultivo tenha surgido nas academias como necessidade de se padronizar o instrumento de identificação cultural para as populações que viviam em países de fala alemã, levou-se algum tempo até que pudesse ser posto em prática.

A busca por uma língua alemã livre de estrangeirismos demonstra uma evolução no processo de construção e sistematização da língua literária alemã (academias) no século XVII. Com esta proposta, o cultivo da língua reconsidera a idéia de que "não há nada que não possa ser dito em alemão", já tornado evidente pela tradução da Bíblia (1534) de Martinho Lutero (14831546). Enquanto Lutero se concentrou em trazer ao público a "palavra de Deus" num registro lingüístico compreensivel para todos, os intelectuais do século XVII concentraram-se na busca pela constituição literária da língua alemã, para que pudessem expressar nela o legado de obras da Antigüidade greco-latina e da Renascença.

A eliminação de estrangeirismos da língua alemã no século XVII foi uma forma de privilegiar uma língua que deveria se desenvolver em termos de expressão literária, com o intuito da sobrevivência cultural e preservação do elemento de identificação dos povos que viviam em países de fala alemã, e compõe parte do cultivo da lingua, responsabilidade das academias. A tradução, vista no século XVII como forma de resgate da literatura da Antigüidade, dentre outras coisas, foi também influenciada por este cultivo.

\section{Agradecimentos}

A Helmut Galle, Luiz Fernando Garcia e Manoel Dias Martins. 


\section{Referências bibliográficas}

BARNER, Wilfried (1970). Barockrhetorik. Studienbuch. Untersuchungen zu ihren geschichtlichen Grundlagen. Tübingen: Max Niemeyer Verlag.

DYCK, Joachim (1988). Ticht-Kunst. Deutsche Barockpoetik und rhetorische Tradition. Bodenheim: Athenaeum Verlag.

HARSDÖRFFER, Georg Ph. Von den Fremden Wörtern. In: Harsdörffer, Georg Ph. (1968). Frauenzimmer Gesprächspiele (herausgegeben von Irmgard Böttcher). Tübingen: Max Niemeyer Verlag, 172-83.

MONTEMAYOR, Jorge de (1970). Los siete libros de la Diana, übersetzt von Hans Ludwig von Kuefstein. Darmstadt: Wissenschaftliche Buchgesellschaft (Originalausgabe 1646). 